\title{
ROTEIRO PARA UMA HISTÓRIA DA EDUCAÇÃO ESCOLAR INDÍGENA: NOTAS SOBRE A RELAÇÃO ENTRE POLÍTICA INDIGENISTA E EDUCACIONAL
}

\author{
LUIZ ANTONIO DE OLIVEIRA* \\ RitA Gomes do NASCIMENTo*
}

\begin{abstract}
RESUMO: O texto visa apresentar um roteiro para a história das políticas educacionais voltadas para os povos indígenas, a partir da consideração das suas relações com as políticas indigenistas. $\mathrm{Na}$ articulação entre os campos indigenista e da educação sugere pensar como as questões das diferenças culturais dos povos indígenas orientaram diferentes projetos de educação escolar indígena. No roteiro proposto, parte-se do período "assimilacionista" e "civilizatório" do início do século XX, marcado pela ideia de uma necessária unidade da nação, passando pelas reformas desta política em que é reconhecida a importância do ensino bilíngue nos processos de escolarização, até o momento atual, caracterizado pela busca do reconhecimento da diversidade cultural como direito fundamental, colocando novos desafios para as políticas educacionais.
\end{abstract}

Palavras-chave: Educação escolar indígena. Indigenismo. Políticas educacionais.

\section{GUIDE TO $A$ History OF INDIGENOUS EDUCATION: NOTES ON THE}

\section{RELATIONSHIP BETWEEN INDIGENOUS AND EDUCATIONAL POLICIES}

ABSTRACT: This work aims to present a guide to the history of educational policies geared towards indigenous peoples based on their interaction with indigenous policies. The relationship between indigenous issues and education suggests considering how matters of cultural differences serve as a basis for different projects of indigenous education. In the proposed guide, the starting point is the "prevailing assimilationist approach" and "civilizing" period of the early 20th century, marked by the idea of a necessary unity of the nation. This period was then followed by this policy's reform wich acknowledged the importance of bilingual education in the

\footnotetext{
* Doutorando em Antropologia e professor da Universidade Federal do Piauí (UFPI). E-mail: luizantov@yahoo.com.br

** Doutora em Educação e membro do Conselho Nacional de Educação (CNE).E-mail: potyguara13@ yahoo.com.br
} 
educational process. Finally, the current moment is characterized by the pursuit of recognition of cultural diversity as a fundamental right, posing new challenges for educational policies.

Key words: Indigenous education. Indigeneity. Educational policies.

TRAME POUR UNE HISTOIRE DE L'ÉDUCATION SCOLAIRE INDIGENE: NOTES SUR LA RELATION ENTRE POLITIQUE INDIGENISTE ET ÉDUCATIVE

RÉSUMÉ: Le texte vise à présenter une trame pour l'histoire des politiques éducatives adressées aux peuples indigènes, à partir de la prise en compte de leurs relations avec les politiques indigénistes. L'articulation entre les champs indigéniste et de l'éducation suggère de penser comment les questions des différences culturelles des peuples indigènes ont orienté différents projets d'éducation scolaire indigène. Dans la trame proposée, on part de la période "assimilationniste" et "civilisatrice" du début du XXème siècle, marquée par l'idée d'une nécessaire unité de la nation, en passant par les réformes de cette politique pour laquelle l'importance de l'enseignement bilingue dans les processus de scolarisation est reconnue, jusqu'au moment actuel, caractérisé par la recherche de la reconnaîssance de la diversité culturelle en tant que droit fondamental, apportant de nouveaux défis pour les politiques éducatives.

Mots-clés: Éducation scolaire indigène. Indigénisme. Politiques éducatives.

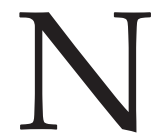

a história das políticas educacionais voltadas para os povos indígenas, as questões das "diferenças" e das "desigualdades" têm motivado diversas ações do Estado. Se, de um lado, podemos dizer que tais políticas tradicionalmente foram orientadas por princípios assimilacionistas em que a educação escolar esteve a serviço da integração dos índios à ordem sócio-histórica, cultural e econômica da sociedade envolvente, de outro, observamos que, na atualidade, a questão da diversidade cultural, como um direito fundamental, vem se constituindo como princípio orientador nos discursos e práticas oficiais. As relações entre o Estado e as populações indígenas, desse modo, no que tange à questão da educação escolar, têm passado por fases que vão da integração, como meta, ao reconhecimento do direito à diferença étnica e cultural dos índios, como princípio de ação política.

Situadas no âmbito das políticas indigenistas do Estado, as políticas educacionais para os povos indígenas expressam a natureza da relação que o Estado pretende estabelecer com tais povos. É necessário, então, entendermos as diretrizes gerais do indigenismo estatal para compreendermos o sentido de suas ações educativas, sobremaneira nos momentos de constituição e de reconfiguração dos campos indigenista e das políticas educativas. Noutros termos, na descrição das diferentes políticas educativas, formando uma história da educação escolar indígena no Brasil, 
precisamos ter em mente quais são as "intenções” do Estado naqueles momentos em relação aos indígenas. Visando a sua assimilação no corpo integrador da nação ou sendo levadas a atender as suas demandas por reconhecimento político de direitos diferenciados, as políticas educacionais, nesse sentido, podem ser tomadas como exemplos das demais ações do Estado em relação aos povos indígenas.

Sabemos que esta relação entre políticas indigenistas e educacionais se configura de forma diversa, em diferentes momentos históricos, mas acreditamos ser fundamental considerá-la para se pensar os processos de construção e implementação das políticas educacionais direcionadas aos povos indígenas. Sendo assim, ao pensar esta relação, um dos aspectos que nos chama a atenção está ligado ao tratamento dado às questões da diversidade dos povos indígenas, bem como os modos desiguais como são tratados em relação aos nacionais e populações regionais no conjunto das políticas públicas.

Tidas como problemas, a "diversidade" e a "desigualdade" ganham evidência nos debates a respeito da ideia de "unidade étnica" que o termo nação tem implicado, de finais de século XIX a começos do XX, nos conflitos "de classe" e territoriais nas fronteiras econômicas do país, nas relações intersocietárias marcadas por diferentes estigmas e preconceitos, na marginalização dos indígenas nos espaços periurbanos, entre outras situações. Em vários destes casos, busca-se na educação a solução para "o problema do índio"1 , com a proposição de modelos educativos adequados aos interesses e necessidades do Estado ou dos projetos societários dos diferentes povos indígenas.

Buscamos tratar neste artigo, partindo da relação entre política indigenista e educativa, algumas ações do Estado na proposição de projetos de Educação Escolar Indígena (EEI) como expressão dos seus modos de relação com os povos indígenas, no âmbito de diferentes compreensões acerca da diversidade e seus status frente à sociedade nacional. Para tanto, dividiremos nossas considerações em dois grandes momentos: um voltado para a descrição das propostas de EEI ofertadas e gestadas por órgãos indigenistas de Estado - Serviço de Proteção aos Índios (SPI) e Fundação Nacional do Índio (Funai) - e outro pelo órgão educacional não indigenista - Ministério da Educação (MEC). Quando necessário, faremos menção aos instrumentos de normatização e legislação que fundamentam as políticas educativas.

Lembramos ainda que a instituição das políticas indigenistas e educacionais não acontece alheia à força do movimento indígena e da mobilização de outras agências indigenistas da sociedade civil. ${ }^{2}$ Esses "outros" têm participado, de diversos modos, na orientação e execução da política educacional indígena. Mesmo não sendo objeto de nossa atenção neste texto, não esquecemos a importância do papel político desses "outros" na construção das histórias da EEI no Brasil, tampouco de suas 
influências para a constituição das políticas educacionais mais atentas à diversidade dos povos indígenas. Reconhecemos, assim, que a trajetória das políticas educacionais - aqui apenas roteirizadas a partir de certas ações estatais - não ocorreu sem a presença e a reação desses "outros".

\section{A educação escolar indígena pelos órgãos indigenistas de Estado (SPI e Funai)}

Na história da relação entre o Estado e os povos indígenas, no tocante às políticas educacionais, podemos considerar o período que vai da primeira década do século XX ao início do seu último decênio como sendo marcado pela atuação dos órgãos indigenistas do Estado na oferta e gestão da EEI. Na articulação proposta entre campo indigenista e educacional, observaremos que a definição da figura do indígena através de sua condição "inferior" e transitória rumo à civilização, bem como por meio dos problemas de contato com as fronteiras econômicas no interior do país, orientará as ações de "proteção fraternal" e tutela a que os povos indígenas estavam submetidos neste momento. Ainda que matizado por certas rupturas, no que se refere às ações educativas e práticas indigenistas correlatas presentes ao longo deste período, nele os modelos de educação escolar são, de um modo geral, "externos" às realidades sociais desses povos.

Sendo assim, o principal objetivo das políticas educativas voltadas para os povos indígenas, das ações catequéticas dos jesuítas no período colonial às práticas indigenistas do século XX, era trazê-los à civilização ou nacionalizá-los. É sob tal imperativo que será instituído o campo indigenista dentro dos aparelhos institucionais do Estado, tendo como pressuposto a inferioridade dos indígenas em relação à raça branca civilizada, estando situados, desta feita, numa fase evolutiva primeva ou selvática. Fora do tempo da nação, os índios eram vistos como estando fadados ao desaparecimento, como sobreviventes de um passado que se queria distante.

Então, tidos como obstáculos ao projeto modernizador do país, os índios estiveram, no momento em que se institucionalizavam as políticas indigenistas brasileiras, no centro de debates que previam a sua extinção (Lima, 1989; 1995). Foi nos embates ideológicos da catequese versus extermínio, criando o "mito de origem" do indigenismo brasileiro, que se instituiu, em 1910, no âmbito do Ministério da Agricultura, Indústria e Comércio (Maic), o Serviço de Proteção aos Índios e Localização dos Trabalhadores Nacionais (SPILTN), chamado, a partir de 1918, apenas de Serviço de Proteção aos Índios (SPI).

Foi assim, ainda durante a Primeira República, que se deu a autonomização do campo do indigenismo através da criação do SPI (Lima, 1995). Em substituição às 
políticas que caracterizaram o regime imperial, descentralizadas nas ações de agentes missionários e coloniais ("diretores gerais de índios", "diretores de aldeias") na administração dos aldeamentos, o SPI visou uma integração laica e "militarizada" das "povoações indígenas" sob o lema da sua proteção contra conflitos intertribais e com os nacionais, bem como o da defesa das fronteiras territoriais do país.

O SPI foi orientado pelo ideário positivista do progresso. É neste sentido que suas ações, visando "proteger" os indígenas "em sua situação transitória rumo à sua incorporação na sociedade nacional", partiam da compreensão dos índios como "brasileiros pretéritos" (Tassinari, 2008, p. 221). Diante de tal entendimento, o contato com os índios tinha o intuito, por meio da "proteção fraternal", de promover um encontro pacífico destes com a civilização, tornando-os aptos para o trabalho com vistas ao progresso e modernização da nação.

No processo de domesticação e civilização dos índios, a educação escolar desempenhou papel privilegiado, não apenas "amansando", mas, principalmente, a) integrando os indígenas à estrutura econômica do país como trabalhadores rurais conhecedores de determinadas técnicas agrícolas e b) incutindo o sentimento de comunhão nacional, sobretudo em regiões de fronteira, tidas como estratégicas na geopolítica do país. Pode-se dizer, com isso, que esta educação escolar para os índios se caracterizava pela "externalidade impositiva de um modelo educacional alheio aos aspectos socioculturais e históricos das populações indígenas" (Nascimento, 2006, p. 40).

Sem levar em conta as diferenças culturais dos grupos étnicos, a proposta de EEI do SPI tinha como intento reduzir as sociodiversidades indígenas a uma diferença genérica perspectivada num mundo rural atrasado. Desse modo, o que interessava ao SPI era, de modo análogo ao que fora realizado pelas expedições da Comissão Rondon, ao longo da primeira década do século XX, o desbravamento e civilização de um Brasil profundo e esquecido, habitado por sertanejos dispersos e grupos indígenas em graus variados de aculturação. Tal intento é atestado na justaposição dos serviços de "Proteção aos Índios" e de "Localização dos Trabalhadores Nacionais" na denominação inicial do órgão indigenista; além de ser facultado aos regionais o acesso às escolas indígenas que, em essência, não diferiam das demais escolas rurais do país.

Contudo, podemos também dizer que o SPI chegou, em determinado momento, não obstante o objetivo precípuo da integração em suas ações, a prestar certa atenção às especificidades indígenas. Avaliando negativamente o modelo educacional adotado, o órgão propôs a reestruturação das suas escolas em 1953.

A partir de então, "para os grupos indígenas menos aculturados" dever-se-ia evitar o termo escola, "para fugir das conotações negativas que esta designação tem 
para os índios, como de um lugar onde se confina as crianças durante longas horas de cada dia, submetendo-os a uma disciplina forçada e em prejuízo de outras atividades que lhes parecem mais úteis", e utilizar "Casa do Índio", que "deverá funcionar como um clube onde homens, mulheres e crianças possam sentir-se à vontade, como em sua própria aldeia". Para isso, foi proposta também a modificação da "planta das escolas" doravante "organizada num prédio próprio sem porta e sem janelas (...) composta de amplo alpendre e dois grandes salões". O primeiro destes "será dotado de máquinas de costura, rodas de oleiro e ferramentas de carpintaria (...) à disposição dos adultos como um lugar de trabalho e de conversa". Já no segundo, "mobiliado com pequenas mesas e cadeiras e para funcionar como salas de aula", as crianças indígenas, "a vista dos pais, se reunirão com o professor para aprenderem português e para serem instruídas na utilização de todas as máquinas e ferramentas da escola e do posto" (SPI, 1953, apud Cunha, 1990, p. 89-90).

Ainda prevendo a criação de "Clubes agrícolas" e incluindo no currículo de suas escolas as disciplinas de "Práticas Agrícolas" para os meninos e "Práticas Domésticas" para as meninas (Cunha, 1990; Ferreira, 2001), o SPI elaborou, no final da década de 1950, um Programa Educacional Indígena que visa, de um modo geral, transformar as escolas indígenas, de "unidades apenas alfabetizadoras, em unidades educacionais mais amplas, oferecendo aos alunos a possibilidade de adquirir conhecimentos mais condizentes com o meio em que habitam" (SPI, 1960, apud Cunha, 1990, p. 93).

De um modo geral, podemos dizer que as políticas educativas do SPI e sua ação de tutela criaram uma crescente situação de dependência dos indígenas. Neste contexto, "Enquanto a educação escolar foi estratégica no processo de pacificação, civilização e nacionalização dessas populações, a escola deixa de ser um investimento prioritário, na medida em que se tornaram sedentárias e dependentes da ação governamental" (Tassinari, 2008, p. 228). O que passou a chamar mais a atenção do órgão indigenista foram os conflitos territoriais em que se viam envolvidos os povos indígenas com a expansão da economia capitalista nas fronteiras do interior do Brasil, relegando suas ações educativas ao segundo plano.

Foi naquele momento, em que os (des)encontros das sociedades indígenas com a nacional ocuparam a atenção da política indigenista, em pleno regime ditatorial, que houve uma redefinição do aparato estatal indigenista com a extinção do SPI, substituído pela Fundação Nacional do Índio (Funai), criada em dezembro de 1967. Proposta como uma inovação na política indigenista do Estado, alvo de críticas locais e internacionais que denunciavam casos de corrupção e maus tratos aos índios, a Funai surgiria como uma resposta da ditadura militar (1964-1985) a tais críticas, dando mostras de como se deu a reestruturação da máquina administrativa do Estado naquele período. O novo órgão, portanto, fazia parte de um plano mais 
abrangente do governo militar que pretendia, a um só tempo, tornar internacionalmente aceita sua política indigenista e cuidar das questões de desenvolvimento econômico e de defesa nacional.

Vinculada ao Ministério do Interior, a Funai, à semelhança do SPI, foi fortemente orientada pelas políticas de integração dos povos indígenas à nacionalidade. Além disso, obedecendo a uma fórmula já presente nas políticas indigenistas anteriores, a Funai organizaria então suas ações de acordo com a lógica segundo a qual o desenvolvimento social, associado ao crescimento econômico, resultaria no desejado processo de civilização dos índios. Ou seja, persistia o objetivo de transformar os indígenas em brasileiros e de favorecer a sua emancipação econômica (Macena, 2007). Nesse sentido, a criação da Funai não resultou em avanços significativos no tratamento da questão da diversidade pelo indigenismo do Estado. ${ }^{3}$

Nos amplos poderes conferidos à Funai pela Lei n. 5.371 de 1967 que a instituiu, estavam a gestão do patrimônio indígena "no sentido de sua conservação, ampliação e valorização"; a realização de estudos e pesquisas sobre o índio e seus grupos sociais; a sensibilização da população nacional para a causa indigenista; o exercício do "poder de polícia nas áreas reservadas e nas matérias atinentes à proteção do índio"; o poder "de representação ou assistência jurídica inerentes ao regime tutelar do índio", além de "promover a educação de base apropriada do índio visando à sua progressiva integração na sociedade nacional".

No que se refere à ação educativa da Funai, podemos dizer que ela foi marcada por ambiguidades em relação ao SPI, uma vez que, por um lado, apresentou continuidades no que diz respeito ao objetivo de assimilação dos indígenas à sociedade nacional e, por outro, reconheceu a importância das línguas nativas nos processos de alfabetização dos indígenas. Para tanto, a Fundação firmou convênio, a partir de 1969 até 1991, com o Summer Institute of Linguistics (SIL), instituição norte-americana de caráter religioso que, desde a década de 1930, vinha desenvolvendo trabalhos de pesquisa linguística com comunidades indígenas latino-americanas. Uma das principais formas de atuação do SIL era através da tradução da Bíblia para as línguas indígenas, numa espécie de retorno à ação missionária que caracterizou os projetos educativos voltados para os povos indígenas no período colonial.

Esta nova política educacional, supostamente mais atenta às sociodiversidades linguísticas dos povos indígenas, foi normatizada por meio da Portaria n. 75/N, de julho de 1972, que considerava "a necessidade da educação bilíngue como instrumento básico de integração" e da regulamentação da grafia indígena, "a mais aproximada possível da grafia do português", uma vez que ela seria um "elemento de transição à língua nacional". Era previsto também, no caso dos povos indígenas falantes do português, o "emprego da língua nacional no desenvolvimento dos programas 
nacionais (...) sem prejuízo de se proporcionar o conhecimento das línguas nativas, como estruturação suplementar". Isto é, o bilinguismo proposto tinha como fim precípuo não exatamente o respeito às diferenças socioculturais e linguísticas dos povos indígenas, mas a melhor aprendizagem dos conteúdos e linguagens nacionais (Brasil, 1972, apud Nascimento, 2012, p. 85-86).

Com a parceria Funai/SIL surgiram, a partir de 1970, os cursos de formação de monitores bilíngues, cuja principal inovação residiu na utilização dos próprios indígenas como professores auxiliares, investindo na formação dos "índios para mediar uma pedagogia que se pretendia bicultural", ainda que estivesse, de fato, a favor dos “interesses civilizatórios do estado" (Nascimento, 2006, p. 41).

Tais cursos, na verdade, consistiam no ensino da leitura e da escrita aos monitores indígenas em suas línguas para que pudessem alfabetizar as crianças de suas comunidades. Entretanto, nas escolas em que atuavam os monitores, os professores não indígenas "desconheciam a função desses profissionais, como também, na grande maioria, não acreditavam no trabalho deles" (Silva, 2006, p. 383). Contudo, a Funai pretendia conseguir, delegando a proposição de um modelo bilíngue de EEI aos especialistas do SIL - o que conferiria a tal modelo "legitimidade científica" e segura eficácia pedagógica -, dessa forma, a almejada integração dos índios à sociedade nacional, sob a aparência de respeito à diversidade linguística e cultural das sociedades indígenas.

Entretanto, não devemos esquecer que, mesmo subordinado ao objetivo de assimilação, o uso das línguas nativas, fazendo surgir a figura do professor indígena (ainda que auxiliar), favoreceria, a posteriori, o desenvolvimento dos projetos de educação escolar dos índios pautados na ideia de autonomia e na construção do protagonismo indígena num modelo educativo diferenciado, mais adequado aos interesses societários de suas comunidades. Neste caso, as políticas educacionais passariam a ser influenciadas por outros atores e agências de mobilização política, com o advento, a partir dos anos de 1970, de novos sujeitos políticos na arena pública nacional, tendo rebatimentos na forma de organização política e administrativa da relação entre indigenismo e políticas educacionais.

Nesta nova relação, a prerrogativa das ações educativas passou da Funai para o MEC, por meio do Decreto n. 26, de 1991. Junto com este vieram outros decretos que, de uma única vez, descentralizaram as ações indigenistas do Estado, que passaram a ser delegadas a diferentes ministérios, esvaziando a Funai de várias de suas atribuições. Algumas das ações do Ministério da Educação, em particular, serão consideradas adiante. Interessa-nos agora pensar a configuração política dos campos indigenista e educativo no que se refere ao papel ainda desempenhado pela Funai naquele momento. 
Convém lembrarmos, então, que o Decreto n. 26, em seu artigo 1º, atribui “ao Ministério da Educação a competência para coordenar as ações referentes à Educação Indígena, em todos os níveis e modalidades de ensino, ouvida a Funai" (destaque nosso). Desse modo, de protagonista, este órgão passou à condição consultiva de ser "ouvido" no campo das políticas de EEI. Contudo, na prática, sua atuação não se limitou ao estabelecido nesta nova "divisão do trabalho" político-administrativo.

Como exemplo disto, podemos citar o que está definido em seu Regimento Interno, aprovado por meio da Portaria n. 542, de 1993, estabelecendo como uma das finalidades da Funai, "promover a educação de base apropriada ao índio" (art. $1^{\circ}$, inciso VI). Na definição deste modelo educativo, a Funai colocava como um dos objetivos para os seus programas educativos "garantir às populações indígenas uma educação escolar diferenciada e que dê acesso aos conhecimentos e ao domínio dos códigos da sociedade nacional, a fim de assegurar-lhes a participação na vida nacional em igualdade de condições" (art. 2º, inciso VI).

Para tanto, a Fundação reservava em seu organograma espaços institucionais voltados especificamente para a administração escolar e apoio pedagógico das escolas indígenas, no âmbito de um Departamento de Educação dentro de sua Diretoria de Assistência (art. 3\% , inciso IV). De acordo com o Regimento, caberia a este Departamento as funções de promoção, elaboração e execução da política nacional de educação escolar indígena, definindo diretrizes, propondo "normas e padrões de educação indígena" às suas unidades locais (art. 76). Além disso, a Coordenação de Administração Escolar do órgão deveria "promover a regularização das escolas indígenas e propor diretrizes e normas para a educação escolar indígena" (art. 77). Entre estas atribuições que a Funai tomava para si, havia ainda a proposição de "currículos específicos, a valorização e/ou revitalização das línguas maternas", bem como o desenvolvimento de "programas voltados à elaboração, produção e adequação de materiais pedagógicos específicos" (art. 78).

Desse modo, mesmo passados mais de dois anos da transferência de suas responsabilidades no campo das políticas educativas para o MEC, a Funai continuou mantendo, em sua estrutura administrativa, instâncias específicas para o tratamento das questões da EEI, situação que perdurou até julho 2012. ${ }^{4}$ Buscando assumir atribuições que seriam dos sistemas de ensino, de acordo com a legislação vigente, bem como fragilizando o sentido de autonomia que vinha sendo construída pelas escolas indígenas na definição de seus projetos de educação diferenciada, a Funai pretendia, conforme o disposto no Regimento de 1993, não apenas definir diretrizes para a política nacional de EEI, mas também elaborar currículos e regularizar escolas.

Vemos, com isso, que a Funai, ao tentar manter suas funções no campo das políticas educacionais, não obstante as reconfigurações institucionais trazidas pelo 
Decreto n. 26, colocava-se em posição de disputa em relação às novas atribuições do MEC. A descentralização das políticas indigenistas, agora setorizadas em ministérios específicos, enfraqueceu o poder tutelar da Funai sobre os índios, cujo capital simbólico, no sentido bourdieuniano, legitimador da posição de poder que ocupava no campo das políticas públicas, passou a competir com outros "capitais" e outras agências que buscavam se mostrar "posicionados" em favor dos direitos dos índios. A respeito da legitimidade destes novos "capitais simbólicos" em disputa por posições de poder no campo político, lembramos do diagnóstico que Kahn (1997, p. 50-51) traçou das políticas educacionais pouco tempo depois destas mudanças. Chamando a atenção para o fato de que "apenas o decreto n. 26 não foi revogado", diz a autora que a falta de apoio dos índios e da sociedade civil em relação a uma possível revogação do referido Decreto se deu em função do "descaso monumental" da Funai com a questão da EEI.

\section{A educação escolar indígena no órgão de Estado não indigenista: a atuação do Ministério da Educação (MEC)}

Na história das políticas educativas voltadas para os povos indígenas, as duas últimas décadas do século $\mathrm{XX}$ foram marcadas por conquistas legais que passam a garantir, no âmbito do que hoje se chama políticas de reconhecimento ou de identidade, o direito à diferença para as populações indígenas. Neste novo horizonte político ganham força as ideias de pluralidade, diversidade, interculturalidade, especificidade e diferenciação como princípios estruturadores dos projetos de educação escolar dos indios, associados aos processos políticos de afirmação identitária dos povos indígenas e de suas autodeterminações.

Neste cenário de conquistas legais é a promulgação da Constituição Federal (CF) de 1988 que inaugura um corpus jurídico-administrativo mais favorável aos processos de reprodução sociocultural e política dos povos indígenas, trazendo novas orientações para as políticas educacionais a eles direcionadas. Ao reconhecer, como direito, a utilização das suas "línguas maternas e processos próprios de aprendizagem", a CF abre caminho para uma legislação educacional mais respeitosa das necessidades e interesses dos povos indígenas.

Estes reconhecimentos de direitos diferenciados postos pela CF e, posteriormente, também, no que se refere especificamente à educação, pela Lei de Diretrizes e Bases da Educação (LDB) $)^{5}$ estavam em consonância com o disposto na Convenção 169 sobre Povos Indígenas e Tribais em Países Independentes, da Organização Internacional do Trabalho (OIT) de 1989, promulgada pelo Brasil em 2004. Afastando-se dos ideais de proteção e integração das populações indígenas e outras populações tribais 
e semitribais, presentes na Convenção 107 de 1957 do mesmo organismo internacional, a Convenção 169 traz avanços significativos para o reconhecimento dos direitos diferenciados dos povos indígenas.

Nesse sentido, a Convenção de 1989 não se refere mais a "populações", termo historicamente associado à ideia de transitoriedade, além de proclamar o direito à autoidentificação, à consulta livre, prévia e informada, o reconhecimento da legitimidade dos próprios povos assumirem o controle de suas instituições, bem como da contribuição dos povos indígenas para a diversidade cultural da humanidade, entre outros avanços. Estas recomendações exercem influência na orientação das políticas educativas e na configuração do campo indigenista brasileiro, ao recomendar, por exemplo, o estabelecimento de um diálogo mais direto das instituições do governo com os povos indígenas, não mais necessariamente mediado por seu órgão indigenista.

No campo da legislação educacional referente à EEI, tais recomendações foram acolhidas, como demonstram as Diretrizes Curriculares Nacionais para a Educação Escolar Indígena na Educação Básica, definidas pelo Conselho Nacional de Educação (CNE) e homologadas pelo MEC em 2012:

O direito das comunidades indígenas de participarem ativamente da elaboração e implementação de políticas públicas a elas dirigidas e de serem ouvidas por meio de consultas livres, prévias e informadas nos projetos ou medidas legais que as atinjam, direta ou indiretamente, coaduna-se com os preceitos que regulamentam o direito à educação escolar diferenciada. Poder decidir e participar no processo de elaboração e implementação de projetos escolares é expressão das novas relações e diálogos estabelecidos entre povos indígenas e Estado nacional. (Parecer CNE/CEB n. 13/2012)

Podemos dizer que, com os documentos surgidos a partir da $\mathrm{CF}$, se inicia um novo capítulo na história da EEI marcado por um maior reconhecimento dos direitos diferenciados dos povos indígenas. Assim, no momento em que é transferida a competência das políticas da EEI da Funai para o MEC, visando à regulamentação de suas ações, é instituída uma Portaria Interministerial do Ministério da Justiça (MJ) e do MEC, onde se reconhece o caráter de aculturação e de destruição dos índios nos processos de escolarização ofertados a eles até então, devendo agora tais processos se constituírem em espaços de reconhecimento étnico e de construção coletiva de conhecimentos que reflitam as expectativas e interesses de cada grupo étnico, fundamentados nas organizações sociais, costumes, línguas, crenças, tradições dos indígenas, bem como nos seus processos próprios de transmissão do saber (Portaria Interministerial MJ/MEC n. 559, 16 abr. 1991).

Ao assumir a coordenação das políticas de EEI, delegando a sua execução para as secretarias de Educação dos estados e dos municípios, o MEC instituiu um 
conjunto de diretrizes orientadoras para este campo. De 1991 para cá foram produzidas as Diretrizes para a Política Nacional de Educação Escolar Indígena (1993), o Referencial Curricular Nacional para as Escolas Indígenas (1998) e os Referenciais para a Formação de Professores Indígenas (2002), definindo os princípios e as propostas pedagógicas e curriculares para as escolas indígenas, ao mesmo tempo em que se orientava os sistemas de ensino para a construção e o desenvolvimento de políticas de EEI, pautadas nas ideias de especificidade, diferenciação, interculturalidade, bilinguismo e escola comunitária.

No âmbito dessas orientações, em 1999, o MEC homologou as Diretrizes Nacionais para o Funcionamento das Escolas Indígenas, elaboradas pelo CNE, que reconhece a EEI como modalidade diferenciada, com normas e ordenamentos jurídicos próprios. Refletindo o contexto escolar da época, estas diretrizes orientavam os sistemas de ensino a responderem as demandas das escolas indígenas que, naquele momento, ofertavam apenas os anos iniciais do ensino fundamental. Em 2012, novas diretrizes para a EEI na educação básica foram definidas pelo CNE. Ligadas às demandas da EEI surgidas nos últimos treze anos, estas apontam para a necessidade da oferta de toda a educação básica nos contextos escolares indígenas, em conformidade com os projetos societários e de escolarização de cada povo.

Além desses documentos, o MEC vem instituindo espaços de participação e de controle social dessas políticas, chamando para o diálogo os próprios indígenas, ONGs, universidades, sistemas de ensino e instituições de pesquisa. Tem sido no diálogo com esses diferentes atores que o MEC vem buscando construir sua política educacional, valendo-se, em grande medida, das experiências educativas das instituições indigenistas, sobretudo os denominados projetos "de autoria" ou "alternati-

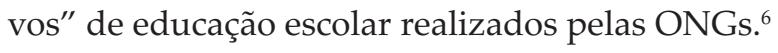

Esse diálogo do MEC com os agentes e agências foi iniciado com a criação do Comitê de Educação Indígena, instituído pela Portaria n. 60, de 1992, no âmbito da sua Secretaria de Educação Fundamental (SEF). Hoje, tal diálogo vem sendo estabelecido, sobretudo, no âmbito da Comissão Nacional de Educação Escolar Indígena (CNEEI), que conta com a participação de representantes indígenas, representantes da Funai, dos sistemas de ensino, de instituições de pesquisa e organizações indigenistas da sociedade civil.

No estabelecimento de uma nova relação entre Estado e povos indígenas não devemos esquecer a abertura de espaços de participação indígena na elaboração e implementação de políticas públicas, como a Coordenação Geral de Educação Escolar Indígena no MEC e a representação indígena na Câmara de Educação Básica (CEB) do CNE. No âmbito local, algumas secretarias de Educação, por orientação do MEC, criaram coordenações com a participação de indígenas; também foram 
instituídos conselhos específicos de EEI em alguns sistemas de ensino, fóruns e outros espaços institucionais em que tem sido assegurada a sua presença.

Com vistas à ampliação deste diálogo, o MEC, em 2009, convocou a I Conferência Nacional de Educação Escolar Indígena (Coneei), ocorrida em Luziânia (GO), no período de 16 a 20 de novembro. A Conferência promoveu uma avaliação da situação da EEI sob uma dupla perspectiva, denominada "a escola que temos" e "a escola que queremos". No primeiro caso, foram apontados avanços e dificuldades; no segundo, diretrizes para a política educacional nos sistemas de ensino. Entre os avanços listados, com destaque para as conquistas legais, estavam o aumento do número de escolas e da presença majoritária dos indígenas na docência e na gestão e os maiores investimentos financeiros do MEC nos programas de construção de escolas, de alimentação escolar e de formação de professores.

Em relação às dificuldades apontadas, ganhou relevo o paradoxo entre o avanço das conquistas no plano legal e a sua não efetiva realização na esfera das políticas implementadas. Algumas das principais reclamações feitas às atuais políticas foram: o não reconhecimento da categoria "professor indígena"; os problemas com transporte e alimentação escolar; o não reconhecimento das escolas indígenas pelos conselhos de Educação, bem como a construção de escolas em desacordo com os padrões socioculturais e ambientais das comunidades indígenas.

Na perspectiva da "escola que queremos", a Coneei apontou para a necessidade de elaboração de novas Diretrizes Curriculares Nacionais para a EEI que contemplasse as realidades atuais, a criação de um sistema próprio de educação e a gestão etnoterritorializada da EEI, esta última já proposta pelo MEC durante a Conferência e instituída por meio do Decreto n. 6.861 de 2009, criando os Territórios Etnoeducacionais (TEEs). Do conjunto destas deliberações, o MEC, em sua atuação pós-conferência, vem assumindo o compromisso de implementar as diretrizes para EEI já homologadas e instituir a política dos TEEs. Já a criação do sistema próprio tem se resumido às discussões da CNEEI.

Outro aspecto a se considerar na atuação do MEC é a distância entre as diretrizes de suas políticas educacionais e as implementações destas políticas pelos sistemas de ensino. Desse modo, os avanços verificados no plano legal parecem não alcançar efetivamente as secretarias e conselhos de Educação no plano de suas ações. Exemplo disso está no fato de que, apesar das diretrizes nacionais atribuírem aos estados a responsabilidade de execução da EEI, sendo facultada aos municípios essa prerrogativa, a maioria das escolas indígenas pertence aos sistemas municipais. Segundo dados do Instituto Nacional de Estudos e Pesquisas Educacionais Anísio Teixeira (Inep), em 2010 existiam 1.508 escolas municipais (53,17\%) e 1.308 escolas indígenas estaduais $(46,13 \%)$. 
Além disso, os conselhos de Educação, em muitos casos, desconsideram as Diretrizes Curriculares Nacionais para a EEI definidas pelo CNE, uma vez que ainda não estabeleceram critérios específicos para o reconhecimento das escolas indígenas e dos cursos de formação de professores, comprometendo a sua legitimação perante os sistemas de ensino e as próprias comunidades indígenas que querem ver suas escolas regularizadas.

Em suma, não obstante a gestão do MEC representar avanços no que tange ao reconhecimento dos direitos diferenciados dos povos indígenas, dando mostras de que a relação entre estes e o Estado vem se estabelecendo em novos moldes, há ainda grandes desafios que precisam ser enfrentados. Um dos principais está ligado à função coordenadora do MEC, que pouco tem se efetivado no âmbito dos sistemas de ensino locais. Tal situação demanda a instituição de mecanismos de acompanhamento e de avaliação na implementação da política educacional nacional coordenada pelo MEC. Em outras palavras, é preciso saber como essas políticas estão sendo executadas pelas secretarias de Educação e normatizadas pelos conselhos; como estão se efetivando no cotidiano das escolas indígenas.

Acreditamos que essas e outras questões precisam ser enfrentadas na perspectiva de superarmos a grande distância que há entre as conquistas obtidas no plano formal e a sua efetivação, cuidando para que estas não se tornem letra morta.

\section{Considerações finais}

Como vimos, as políticas educacionais voltadas para os povos indígenas, orientadas por diferentes princípios ao longo de sua história, colocam questões importantes para pensarmos o sentido político das diferenças culturais, seja nos casos em que, deliberadamente, se tenta negá-las ou nos momentos em que se busca afirmá-las como valor ético e democrático para a construção de uma sociedade plural. Nesse sentido, o roteiro proposto para uma história da educação escolar indígena, aqui apenas sugerido, buscou partir das "intenções" do Estado para descrever as suas ações educativas.

Acreditamos ser este um caminho possível para refletirmos melhor sobre os diferentes poderes em jogo na construção das políticas educacionais. Poderes estes em disputas por posições privilegiadas na configuração do campo institucional das políticas públicas, no qual SPI, Funai e MEC buscaram, cada um em seu tempo e a seu modo, fazer valer seus respectivos "capitais simbólicos" na definição do trato das questões educativas: progresso e integração para o primeiro, desenvolvimento econômico e bilinguismo para o segundo e direitos educacionais diferenciados e "correção das desigualdades" para o terceiro. 
Sabemos, desde Bourdieu (1996, p. 52), que tais capitais simbólicos, de natureza ideológica, são manipulados num campo de lutas de poder em que os diferentes agentes buscam "ocupar posições dominantes no interior de seus respectivos campos", no sentido de aumentar ou conservar seu capital. Neste mercado de capitais simbólicos, as categorias de igualdade e diferença articulam novas demandas políticas, exigindo do Estado a capacidade de conjugar "unidade" e "pluralismo". Desse modo, as questões das diferenças culturais passam a fazer parte dos discursos instituidores das políticas do Estado.

\section{Notas}

1. A expressão "problema do índio", ou mais exatamente "problema indígena", utilizada por Darcy Ribeiro para se referir aos resultados do "encontro dos índios com a civilização", diz respeito às contradições ou conflitos adaptativos decorrentes deste contato em que se colocava como questão a "transfiguração étnica" dos indígenas ou sua "integração no Brasil moderno". Para esta posição, ver Ribeiro (1986).

2. Sobre o assunto, ver Silva (1999), Ferreira (2001) e Silva (1994).

3. Exemplo disso é observado na formulação do Estatuto do Índio (Lei n. 6.001), aprovado em setembro de 1973, que traz em seu artigo 50 a determinação de que "A educação do índio será orientada para a integração na comunhão nacional mediante processo de gradativa compreensão dos problemas gerais e valores da sociedade nacional, bem como do aproveitamento das suas aptidões individuais". O Estatuto estabelece ainda, em seu artigo 52 que "Será proporcionada ao índio a formação profissional adequada, de acordo com o seu grau de aculturação".

4. A Coordenação Geral de Educação (CGE) da Funai deixou de existir com a aprovação do seu novo estatuto, por meio do Decreto n. 7.778, de 27 de julho de 2012. No tocante à educação, caberá agora à Diretoria de Promoção e Desenvolvimento Sustentável do órgão indigenista, bem como às suas Coordenações Regionais, monitorar e apoiar as políticas de educação escolar indígena realizadas pelos estados e municípios, em articulação com o Ministério da Educação.

5. A LDB, Lei n. 9.394, de dezembro de 1996, reafirma o direito dos povos indígenas utilizarem "suas línguas maternas e processos próprios de aprendizagem", dedicando ainda dois de seus artigos (78 e 79) aos programas de educação escolar indígena e seus objetivos.

6. O projeto "Experiência de autoria", desenvolvido pela Comissão Pró-Índio do Acre, é referência neste campo, servindo de modelo para as políticas educativas do MEC. A respeito do projeto, consultar: <http://www.cpiacre.org.br/1/>.

\section{Referências}

BOURDIEU, P. Razões práticas: sobre a teoria da ação. Campinas: Papirus, 1996.

BRASIL. Constituição (1988). Constituição da República Federativa do Brasil. 35. ed. Brasília, DF: Câmara dos Deputados, 2012. Disponível em: <http://bd.camara.gov.br/ bd/bitstream/handle/bdcamara/1366/constituicao_federal_35ed.pdf?sequence=26>. Acesso em: 8 ago. 2012.

BRASIL. Decreto n. 26, de 4 de fevereiro de 1991. Dispõe sobre a Educação Indígena no Brasil. Diário Oficial da União, Brasília, DF, 5 fev. 1991. n. 25, Seção 1, p. 2487. 
BRASIL. Decreto n. 6.861, de 27 de maio de 2009. Dispõe sobre a Educação Escolar Indígena, define sua organização em territórios etnoeducacionais, e dá outras providências. Diário Oficial da União, Brasília, DF, 28 fev. 2009. n. 100, Seção 1, p. 23.

BRASIL. Lei n. 5.371, de 5 de dezembro de 1967. Autoriza a instituição da "Fundação Nacional do Índio" e dá outras providências. Diário Oficial da União, Brasília, DF, 6 dez. 1967. Seção 1, p. 12223.

BRASIL. Lei n. 6.001, de 19 de dezembro de 1973. Dispõe sobre o Estatuto do Índio. Diário Oficial da União, Brasília, DF, 21 dez 1973. n. 244, Seção 1, p. 13176-13180.

BRASIL. Lei n. 9.394, de 20 de dezembro de 1996. Estabelece as diretrizes e bases da educação. Diário Oficial da União, Brasília, DF, 23 dez. 1996. Seção 1, 27833-27841.

BRASIL. Ministério da Educação. Secretaria de Educação Fundamental. Diretrizes para a Política Nacional de Educação Escolar Indígena. Brasília: MEC/SEF, 1993. 22p. (Cadernos Educação Básica, série institucional, 2).

BRASIL. Ministério da Educação. Parecer CNE/CEB n. 13/2012. Diretrizes Curriculares Nacionais para a Educação Escolar Indígena na Educação Básica. Diário Oficial da União, Brasília, DF, 15 jun. 2012. Seção 1, p. 18.

BRASIL. Portaria Interministerial n. 559, de 16 de abril de 1991. Sobre a educação escolar para as populações indígenas. Diário Oficial da União, Brasília, DF, 17 abr. 1991. n. 73, Seção 1, p. 7084-7085.

BRASIL. Portaria n. 542, de 21 de dezembro de 1993. Aprova o Regimento Interno da Fundação Nacional do Índio - Funai. Diário Oficial da União, Brasília, DF, 22 dez. 1993. n. 243, Seção 1, p. 20039.

CUNHA, L.O.P. A política indigenista no Brasil: as escolas mantidas pela Funai. 1990. 129f. Dissertação (Mestrado em Educação) - Faculdade de Educação, Universidade de Brasília, Brasília, DF.

FERREIRA, M.K.L. A educação escolar indígena: um diagnóstico crítico da situação no Brasil. In: SILVA, A.L.; FERREIRA, M.K.L. (Org.). Antropologia, História e Educação: a questão indígena e a escola. São Paulo: Global, 2001. p. 71-111.

KAHN, M. Educação indígena. Cadernos de Pesquisa em Educação, São Paulo, n. 7, p. 49-63, 1997. Disponível em: <http://www.cebrap.org.br/v2/files/upload/biblioteca_virtual/ educacao_indigena.pdf $>$. Acessso em: 08 ago. 2012.

LIMA, A.C.S. Os museus de história natural e a construção do indigenismo: notas para uma sociologia das relações entre campo intelectual e campo político no Brasil. Rio de Janeiro, 1989 (mimeo.). 
LIMA, A.C.S. Um grande cerco de paz: poder tutelar, indianidade e formação do Estado no Brasil. Petrópolis: Vozes, 1995.

MACENA, J.M.O. "Isso é coisa de vocês": os índios Canela e a escola. 2007. 139f. Dissertação (Mestrado em Antropologia) - Departamento de Antropologia, Universidade de Brasília, Brasília, DF.

NASCIMENTO, A.M. Português intercultural: fundamentos para a educação linguística de professores e professoras indígenas em formação superior específica numa perspectiva intercultural. 2012. 477f. Tese (Doutorado em Letras) - Faculdade de Letras, Universidade Federal de Goiás, Goiânia.

NASCIMENTO, R.G. Educação escolar dos índios: consensos e dissensos no projeto de formação docente Tapeba, Pitaguary e Jenipapo-Kanindé. 2006. 140f. Dissertação (Mestrado em Educação) - Departamento de Educação, Universidade Federal do Rio Grande do Norte, Natal.

RIBEIRO, D. Os índios e a civilização: a integração das populações indígenas no Brasil moderno. Petrópolis: Vozes, 1986.

SILVA, M.F. A conquista da escola: educação escolar e movimento de professores indígenas no Brasil. Em Aberto, Brasília, DF, v. 14, n. 63, p. 38-53, 1994.

SILVA, M.S.P. As línguas indígenas na escola: da desvalorização à revitalização. Signótica, Goiânia, v. 18, n. 2, p. 381-395, 2006.

SILVA, R.H.D. A autonomia como valor e articulação de possibilidades: o movimento dos professores indígenas do Amazonas, de Roraima e do Acre e a construção de uma política de educação escolar indígena. Cadernos Cedes, Campinas, v. 19, n. 49, p. 62-75, 1999.

TASSINARI, A.M.I. A educação escolar indígena no contexto da antropologia brasileira. Ilha: Revista de Antropologia, Florianópolis, v. 10, n. 1, p. 217-245, 2008.

Recebido em 9 de agosto de 2012.

Aprovado em 24 de agosto de 2012. 